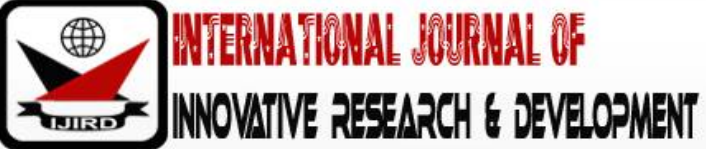

ISSN 2278-0211 (Online)

\section{An Expert System for Rural Water Supply Management}

\author{
Ogunlela, Ayodele Olanrewaju \\ Professor, Department of Agricultural \& Biosystems Engineering, \\ University of Ilorin, Ilorin, Nigeria \\ Awoniyi, Gbenga Olabanjo \\ Lecturer, Department of Agricultural and Bio-Environmental Engineering, \\ Federal Polytechnic, Bida, Niger State, Nigeria
}

\begin{abstract}
:
Most of the rural settlers are faced with the problem of potable water supply due to the high cost of water management (construction, installation and maintenance), thereby, the villagers are involved in taking unpurified water from streams and open wells which may eventually affect their health. This necessitated the need for a better system. An expert system was suggested which involves purification of stream water through a specially-designed reservoir and sedimentation tank. The system was a complete water supply chain network that made used of an Integrated Development Environment (IDE) interactive phase through sensors and simulation; to diagnose and execute problems in the system setup. It also provided for irrigation and minor farm activities for the surrounding farm settlers to minimize water wastage.
\end{abstract}

Keywords: Expert system, water management, rural

\section{Introduction}

An expert system could be regarded as a helper to human expert. It does its functions by grasping basic information from human to solve complex problems in a shorter time.

Akhund, AbdulRahman and Memon (2014); Yelapure and Kulkarni (2012), Nilsson (2010); affirmed that expert system should be able to interact with human expert, make reasonable guesses and decisions, interpret, diagnose and monitor a designed plan as human expert would do.

Expert systems were among the first truly successful forms of Artificial Intelligence (AI) software (Kuman \& Jain, 2012;Nilsson, 2010;McCorduck, 2004). The first expert systems were created in the 1970s and then increased in circulation around 1980s(Zhao, Mao, Lin, Yin \& Xu, 2020). Nwigbo and Agbo (2011) said that an expert system has two components: the inference engine and the knowledge base.

Peter J. F. Lucas (2014) asserted that expert system are those that are capable of providing advice and or solution to certain problem in a specific domain in a way that is comparable to human expert. Abdullah, Abdullah, Marion, Quiedat and Chauvet (2020) developed a weather forecasting model using a time series method ARIMA (Auto Regressive Integrated Moving Average) thereby forecasted minimum daily temperature. Geographic Information System (GIS) has been used with an expert system to simulate water supply (Ramesh, Santhosh \& Jagadeesh; 2012). Also, automated planning was used for optimization of machine tools error planning (Parkinson \& Longstaff, 2015). Yelapure and Kulkarni (2012) reviewed a number of expert systems such as CUPTEX, CITEX, NEPER Wheat, among others. Wei, Feng and Yuan (2020) solved a complex optimization problem on a constraint differential evolution using a single constraint algorithm.

Investigation has shown that a lot of bacteria are consumed by the skin on the surface of sand called 'Schmutzdecke' which comprises algae, diatoms, protozoa and other organisms. Each cubic metre of sand provides 15,000 $\mathrm{m}^{2}$ of surface area for adsorption of bacteria to take place (Morgan, 1990). Due to the fact that sand inherits the natural quality to purify water, it was being used for local purification and filtration of water (Oluwande, 1983). Sand filtration is simple to use and can possesses low maintenance requirement (Centres for Diseases Control and Prevention, 2014).

The major objective of this work was to incorporate an expert system in rural water supply and management for improved efficiency and sustainability. Other objectives were to develop and interactive system to ease water supply, use and management; develop an independent purifying reservoir through slow sand filtration technique; and develop a sensitive reservoir and water tank units. 


\section{Methodology and Analysis for Designs}

The framework for the expert system is shown in Figure 1, with the schematic diagram in Figure 2.

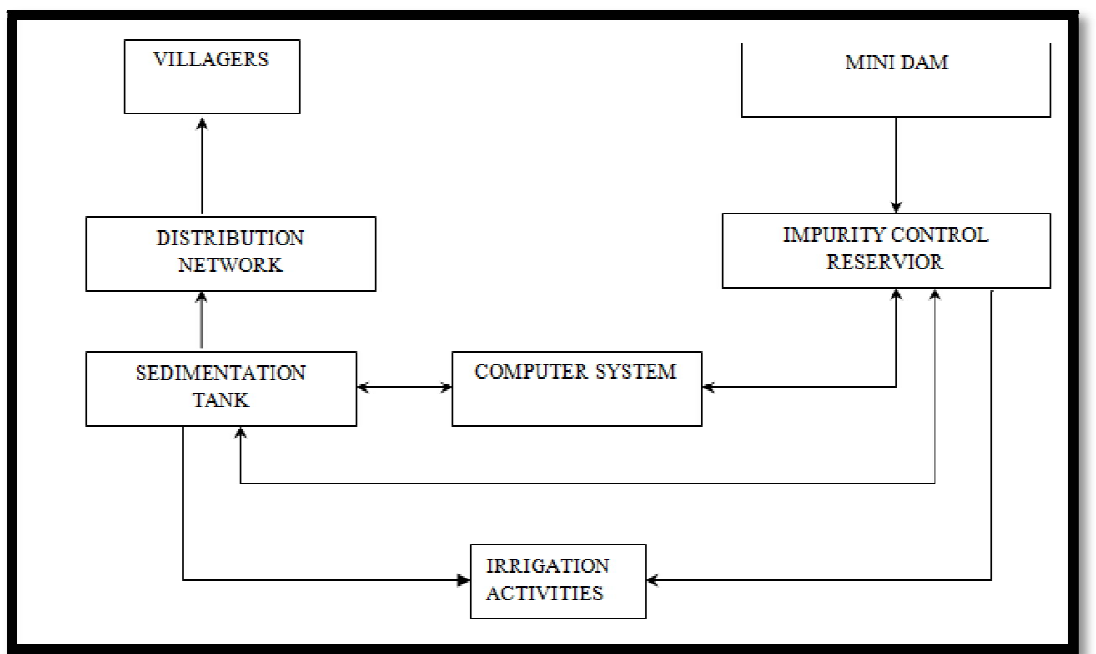

Figure 1: Expert System for Water Management

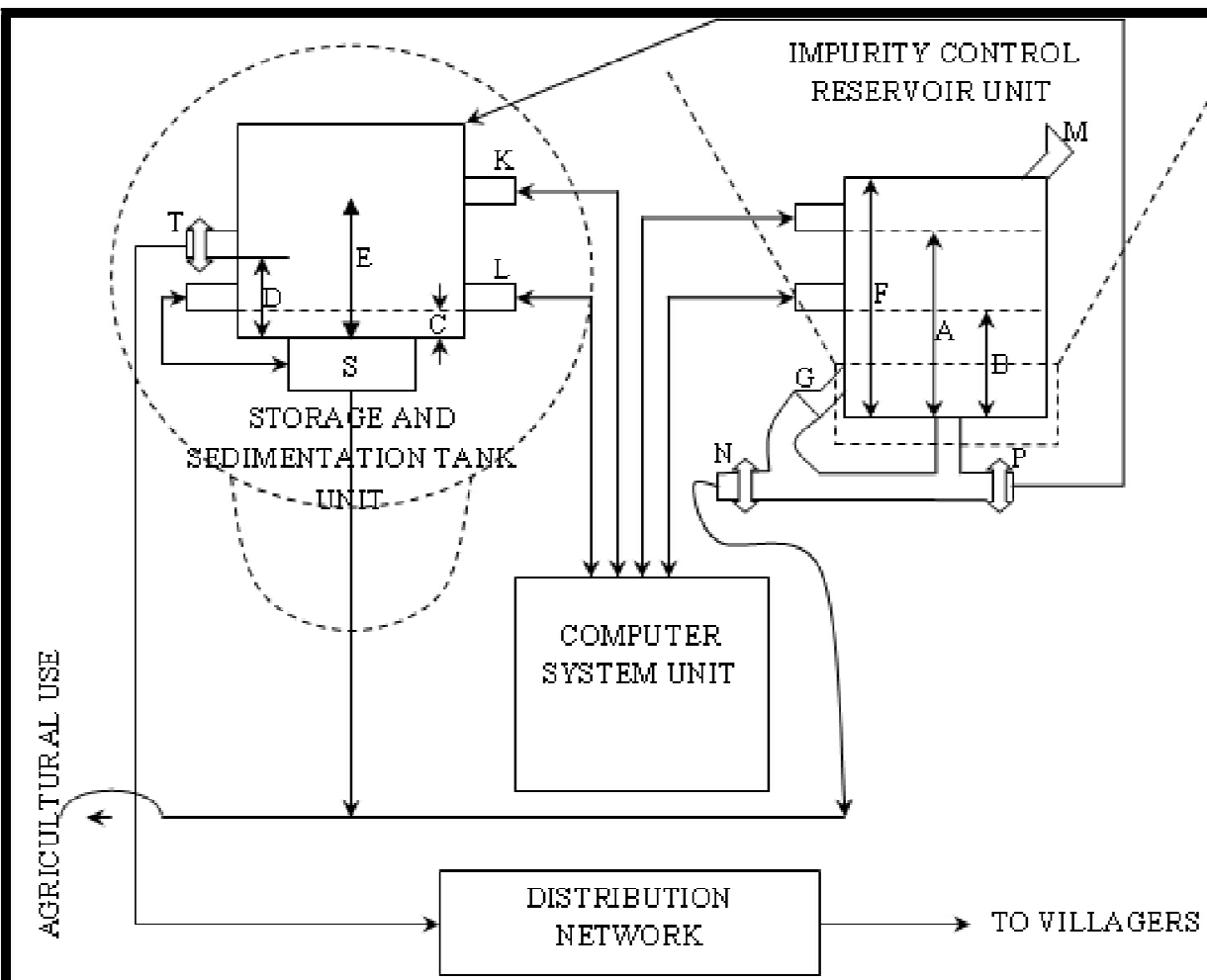

KEY:

$A=$ Maxituum height of flow

$\mathrm{B}=\mathrm{M}$ inimum height of flow

$\mathrm{C}=$ Maximutu height of seditnent

$\mathrm{D}=$ Minitmum depth of flow in tark

$\mathrm{E}=\mathrm{V}_{\mathrm{ary}} \mathrm{ing}$ seditrent level

$\mathrm{F}=$ Tatying height of flow

$\mathrm{G}=$ Flush gate

$\mathrm{I}=$ Lower sensor

$\mathrm{J}=\mathrm{Upper}$ sensor

$\mathrm{K}=$ Minitmum flow depth detector

$\mathrm{L}=$ Sediment sensor

$\mathrm{M}=$ Reservoir irlet tap (From miri dam)

$\mathrm{N}=\mathrm{F}$ lush outlet tap (To irrigation discharge pipe),

$\mathrm{P}=$ Discharge Tajt

$\mathrm{R}=$ water level in the storage and sedimentation tark

$S=$ Back-wash Opering

$\mathrm{T}=$ Distribution tap

\section{Figure 2}




\subsection{Storage and Purifying Medium}

The storage and purifying medium were classified into two, namely: primary purifier (impurity control reservoir) and secondary purifier (storage and sedimentation tank).

\subsection{Impurity Control Reservoir (Purification Reservoir)}

This is the primary purifier (water purifier) in the system. It was designed of both trapezoidal and rectangular channel principles in which slow sand filter serves as the impurity control. It is divided into two: trapezoidal chamber and rectangular Chamber. The rectangular chamber represents the filtration and purification chamber which contains a column of well-graded gravel (of effective size between $8 \mathrm{~mm}$ and $64 \mathrm{~mm}$ ) between $30 \mathrm{~cm}-45 \mathrm{~cm}$ thick and a column of sand (of effective size between $0.25 \mathrm{~mm}$ and $0.35 \mathrm{~mm}$ ) between $60 \mathrm{~cm}-120 \mathrm{~cm}$ thick. Other features such as sensors (water level detectors), flush gate, water inlet pipe (conveyance pipe from dam), water outlet pipes (storage and irrigation discharge pipes) were incorporated.

\subsection{Storage and Sedimentation Tank}

This was also known to be secondary water purifier in the system. It was designed to be spherical in shape, to allow for quick settlement of sediment and easy backwash of the tank. Features like sedimentation sensor, minimum flow depth sensor, backwash opening, distribution tap and pipe leading to the irrigation discharge pipe were fixed in.

\subsection{Design Analysis of Purification Reservoir (Impurity Control Reservoir)}

The Purification Reservoir design specification was based on three factors: shape, materials for construction and reservoir capacity.

\subsubsection{Shape}

The design for the purification reservoir made use of both trapezoidal and rectangular channel principles. The reservoir is divided into two sections: section 1 (trapezoidal chamber) and section 2 (rectangular chamber which represents the filtration and purification chamber). The trapezoidal chamber was designed to have a slope angle of $45^{\circ}$ (Figure3).

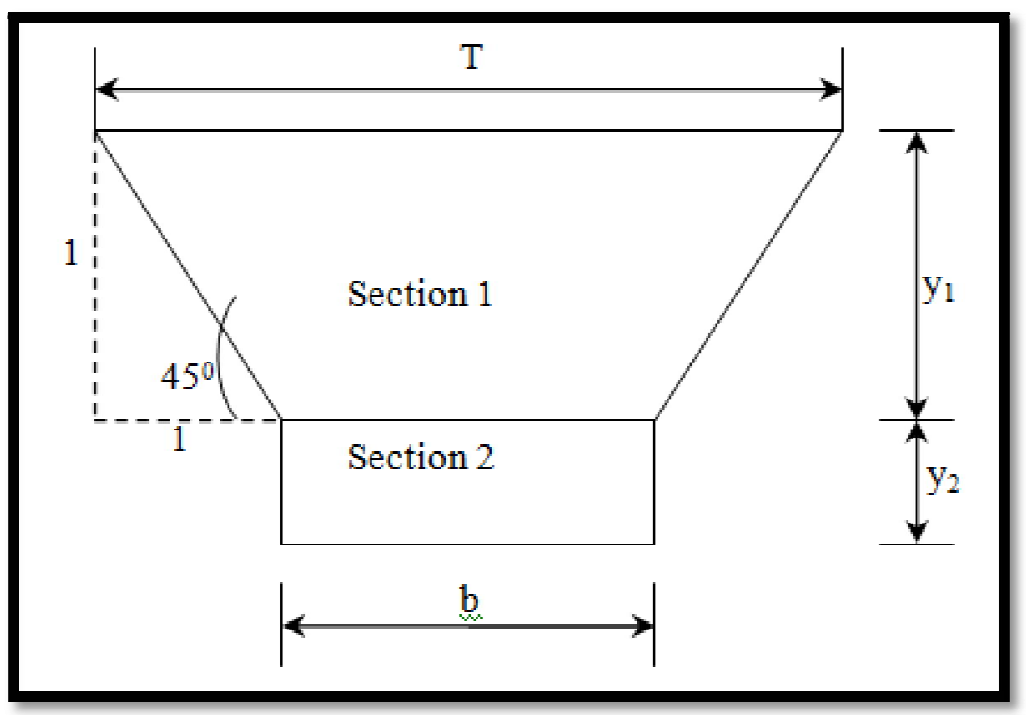

Figure 3: Impurity Control Reservoir Chambers

By combining section 1 and section 2 parameters, we arrive at the total parameters of the whole impurity control reservoir as analyzed below:

Area of the Reservoir,

$\mathrm{A}=\mathrm{y}_{1}\left(\mathrm{~b}+\mathrm{y}_{1}\right)+\mathrm{by}_{2}$

$$
\begin{array}{lc}
\text { Area of the Reservoir, } & \mathrm{A}=\mathrm{A}_{1}+\mathrm{A}_{2} \\
\begin{array}{l}
\mathrm{A}=\mathrm{y}_{1}\left(\mathrm{~b}+\mathrm{y}_{1}\right)+\mathrm{by}_{2} \\
\text { Wetted Perimeter of the reservoir, }
\end{array} & \mathrm{P}=\mathrm{P}_{1}+\mathrm{P}_{2}-\mathrm{b} \\
\mathrm{P}=2 \mathrm{y}_{1} \sqrt{2}+2 \mathrm{y}_{2}+\mathrm{b} & \\
\begin{array}{l}
\text { Hydraulic Radius of the Reservoir, } \\
\mathrm{R}=\frac{\mathrm{y}_{1}\left(\mathrm{~b}+\mathrm{y}_{1}\right)}{\mathrm{b}+2 \mathrm{y}_{1} \sqrt{2}}+\frac{\mathrm{by} \mathrm{y}_{2}}{\mathrm{~b}+2 \mathrm{y}_{2}}
\end{array} & \mathrm{R}=\mathrm{R}_{1}+\mathrm{R}_{2} \\
\begin{array}{l}
\text { Hydraulic Depth of the Reservoir, } \\
\text { Houlic }
\end{array} & \mathrm{D}=\mathrm{D}_{1}+\mathrm{D}_{2}
\end{array}
$$$$
=2 y_{1} \sqrt{2}+2 y_{2}+b
$$$$
\mathrm{R}=\frac{\mathrm{y}_{1}\left(\mathrm{~b}+\mathrm{y}_{1}\right)}{\mathrm{b}+2 \mathrm{y}_{1} \sqrt{2}}+\frac{\mathrm{by}_{2}}{\mathrm{~b}+2 \mathrm{y}_{2}}
$$

$\mathrm{D}=\frac{\mathrm{y}_{1}\left(\mathrm{~b}+\mathrm{y}_{1}\right)}{\mathrm{b}+2 \mathrm{y}_{1}}+\mathrm{y}_{2}$

\subsection{Analysis for the Design of Storage and Sedimentation Tank}

The tank was designed as circular in plan area. This would allow for quick settlement of sediments and easy backwash of the tank. 


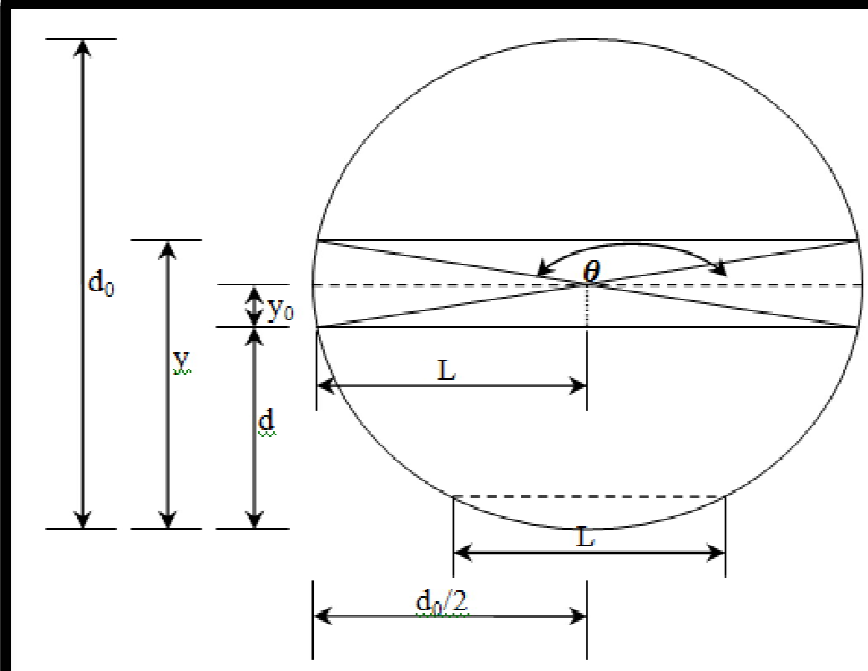

Figure 4: Storage and Sedimentation Tank Design Analysis

where:

$\mathrm{d}_{0}=$ tank diameter

$\mathrm{d}=$ minimum flow depth for water discharge

$\mathrm{y}=$ depth of water in tank

$\mathrm{y}_{0}=$ sediment level in the tank

$\mathrm{y}_{0}=\frac{\mathrm{d}_{0}}{50}=\frac{\mathrm{d}}{23}$ (for maximum flow)

Note: $\theta=2 \operatorname{Cos}^{-1}\left(\mathrm{y}_{0} / \mathrm{d}_{0}\right)$

The total area of tank at partially filled, $\quad A_{p}=$ area of sector occupied by fluid and sediment $A_{p}=\left(\frac{2 \pi-\theta}{8}\right) d_{0}^{2}(\theta$ in radian $)$

The maximum area for sediment, $\quad \mathrm{A}_{\mathrm{s}}=\mathrm{Ly}_{0}$

where $\mathrm{L}=$ length of the segment subtended by the flow

$\mathrm{L}=\frac{\mathrm{d}_{0}}{50} \sqrt{624}$

therefore, $\mathrm{A}_{\mathrm{s}}=\frac{\mathrm{d}_{0} \mathrm{y}_{0}}{50} \sqrt{624}$

The area for minimum flow depth, $\quad \mathrm{A}_{\mathrm{f}_{\mathrm{m}}}=$ Area of flow - Maximum area for sediment

$A_{f_{m}}=\frac{\theta d^{2}}{8}-\frac{d_{0} y_{0}}{50} \sqrt{624}$

The area cover by liquid (water) at any time, $t, A_{l}=A_{p}-A_{f_{m}}$

$\mathrm{A}_{1}=\mathrm{d}_{0}^{2}\left(\frac{\pi-\theta}{4}\right)+\frac{\mathrm{d}_{0} \mathrm{y}_{0}}{50} \sqrt{624}$

Area covered by sediment at time, $\mathrm{t}, \quad \mathrm{A}_{\mathrm{st}_{\mathrm{t}}}$ :

therefore, $\mathrm{A}_{\mathrm{s}_{\mathrm{t}}}=\frac{23}{\mathrm{~A}_{\mathrm{f}_{\mathrm{m}}}}$

Note:

$\theta$ in radians

Impurity control reservoir composed of the followings:

Reservoir wall: This was designed of tin or zinc in order to make it portable. The wall material must be galvanized in order to give high and good resistance to corrosion.

Reservoir filter material/filter medium: The filter was made of gravel and sand columns. A slow sand filter (effective size between $0.25 \mathrm{~mm}-0.35 \mathrm{~mm}$ and coefficient of uniformity between 2 and 3) was adopted of which sand was a medium size with non-colloidal particles and $60 \mathrm{~cm}-120 \mathrm{~cm}$ thick column on top of gravel. The gravel was $30 \mathrm{~cm}-45 \mathrm{~cm}$ thick in the rectangular section of the reservoir which serves as the filtration chamber.

Conveyance medium material: This was made of plastic pipe network and pumps. The pipe can be made of steel, ceramic or plastic materials depending on the availability. The pipe conveying water from the mini dam should be slightly larger or the same diameter with the discharge outlet pipe. The pumps should be of adequate capacities with the pumping criteria. 
Flush gate: The flush gate was made of zinc with a very high-power locking facility and the opening lines must be cemented with gum to minimize water leakage. The gate must be electroplated to provide good resistance to wear and water abrasion.

\subsection{Design Analysis for Water Quantity}

The design for water quantity used for this work made used of the following considerations:

- The population of the geographical location.

- The population growth rate of the area.

- The average reasonable water consumption per day per person.

- The water wastage problems.

The maximum population for an effective design is given by:

$\mathrm{P}=\mathrm{P}_{0}(1+\mathrm{r})^{\mathrm{n}}$

where:

$\mathrm{P}=$ maximum population,

$\mathrm{P}_{0}=$ present population,

$\mathrm{n}=$ number of effective years for the design,

$\mathrm{r}=$ population growth rate

The total water consumption per day is given as:

$\mathrm{Q}=\mathrm{P}\left(\mathrm{Q}_{0}+0.1 \mathrm{Q}_{0}\right)$

where:

$\mathrm{Q}_{0}=$ total water consumption per day per person,

$0.1 Q_{0}=10 \%$ water wastage clearance

\section{Results and Discussion}

\subsection{Results}

Impurity control reservoir parameters indicated in equation (1), (2), (3) and (4) together with the analytical models for storage and sedimentation tanks as indicated in equation (5), (6), (9), (10), (11) and (12) respectively were incorporated in form of a simple artificial intelligent to interpret and diagnose the Maximum height of flow, A, Minimum height of flow, B and Varying height of flow, F; as in impurity control reservoir, and Maximum height of sediment, C, Minimum depth of flow in tank, D and Varying sediment level, E as in storage and sedimentation tank respectively. Programs 1 and 2, and output 1 and 2 shows the resulted simulation interactive phase of the expert system.

\subsubsection{Program 1}

REM: 'EXPERT SYSTEM FOR RURAL WATER SUPPLY MANAGEMENT (IMPURITY CONTROL RESERVOIR UNIT)'

1 CLS: PRINT

2 PRINT 'EXPERT SYSTEM FOR RURAL WATER SUPPLY MANAGEMENT'

3 PRINT 'PROGRAM TO STIMULATE IMPURITY CONTROL RESERVOIR UNIT'

4 DIM A AS INTEGER, B AS INTEGER, F AS INTEGER

5 PRINT 'A = Maximum height of flow';

6 PRINT ' $\mathrm{B}=$ Minimum height of flow'

7 PRINT ' $\mathrm{C}=$ Maximum height of sediment'

8 PRINT 'D = Minimum depth of flow in tank'

9 PRINT 'E = Varying sediment level'

10 PRINT ' $F$ = Varying height of flow'

11 PRINT ' $G$ = Flush gate'

12 PRINT ' $M=$ Reservoir inlet tap'

13 PRINT 'N = Flush outlet tap'

14 PRINT 'P = Discharge tap'

15 PRINT ' $\mathrm{R}=$ Water level in the Storage and Sedimentation tank'

16 PRINT 'S = Backwash opening'

17 PRINT 'T = Distribution tap': GOTO 18

18 INPUT A: INPUT B: INPUT F: PRINT 'A='; A; 'cm': PRINT 'B='; B; 'cm': PRINT 'F='; F; 'cm'

19 IF $\mathrm{F}<\mathrm{B}$ GOTO 30 ELSE GOTO 37

20 IF F > A GOTO 21 ELSE GOTO 31

21 PRINT 'RESERVOIR REQUIRES MAINTENANCE'

22 PRINT 'OPEN FLUSH OUTLET TAP, N'

23 PRINT 'CLOSE DISCHARGE TAP, $\mathrm{P}$ '

24 PRINT 'OPEN FLUSH GATE, G'

25 PRINT 'OPEN RESERVIOR INLET TAP, M'

26 PRINT 'PUMP WATER FROM DAM'

27 PRINT 'DISTRIBUTE WATER FOR AGRICULTURAL USE'

28 FOR i = 1 TO 20: PRINT 'i='; i; 'min'

29 NEXT i 
30 PRINT 'CHANGE FILTER'

31 PRINT 'FILTER QUALITY OK'

32 PRINT 'OPEN DISCHARGE TAP, $\mathrm{P}$ '

33 PRINT 'CLOSE RESERVIOR INLET TAP, M'

34 PRINT 'CLOSE FLUSH OUTLET TAP, N'

35 PRINT 'DISCHARGE TAP, P SHOULD REMAIN CLOSED'

36 PRINT 'CLOSE FLUSH GATE, G'

37 PRINT 'OPEN RESRVOIR INLET TAP, M'

38 PRINT 'PUMP WATER INTO RESERVOIR'

39 PRINT 'OPEN DISCHARGE TAP, $\mathrm{P}$ '

40 PRINT 'IMPURITY CONTROL RESERVOIR READY FOR USE'

41 PRINT 'YOU CAN DISTRIBUTE WATER TO STORAGE AND SEDIMENTATION TANK'

42 PRINT: PRINT

43 END

3.1.2. Program 2

REM: 'EXPERT SYSTEM FOR RURAL WATER SUPPLY MANAGEMENT (STORAGE AND SEDIMENTATION TANK UNIT)'

1 CLS: PRINT

2 PRINT 'EXPERT SYSTEM FOR RURAL WATER SUPPLY MANAGEMENT'

3 PRINT 'PROGRAM TO STIMULATE STORAGE AND SEDIMENTATION TANK UNIT'

4 DIM C AS INTEGER, D AS INTEGER, E AS INTEGER, R AS INTEGER

5 PRINT 'A = Maximum height of flow';

6 PRINT 'B = Minimum height of flow'

7 PRINT ' $\mathrm{C}=$ Maximum height of sediment'

8 PRINT 'D = Minimum depth of flow in tank'

9 PRINT ' $E$ = Varying sediment level'

10 PRINT ' $\mathrm{F}$ = Varying height of flow'

11 PRINT ' $G$ = Flush gate'

12 PRINT 'M = Reservoir inlet tap'

13 PRINT 'N = Flush outlet tap'

14 PRINT 'P = Discharge tap'

15 PRINT ' $\mathrm{R}=$ Water level in the Storage and Sedimentation tank'

16 PRINT 'S = Backwash opening'

17 PRINT 'T = Distribution tap': GOTO 18

18 INPUT C: INPUT E: PRINT 'C='; C; 'cm': PRINT 'E='; E; 'cm'

19 IF E < C GOTO 29 ELSE GOTO 20

20 PRINT 'STORAGE AND SEDIMENTATION TANK REQUIRES MAINTENANCE'

21 PRINT 'OPEN BACK WASH OPENING, S'

22 PRINT 'CLOSE DISTRIBUTION TAP, T'

23 PRINT 'DISTRIBUTE WATER FOR AGRICULTURAL USE'

24 FOR i = 1 TO 20: PRINT 'i='; i; 'min'

25 NEXT i

26 PRINT 'CLOSE DISCHARGE TAP, P'

27 PRINT 'CLOSE BACKWASH OPENING, S'

28 PRINT 'OPEN DISCHARGE TAP, $\mathrm{P}$ '

29 PRINT 'OPEN DISTRIBUTION TAP, T'

30 PRINT 'STORAGE AND SEDIMENTATION TANK IN GOOD CONDITION'

31 PRINT 'YOU CAN DISTRIBUTE WATER FOR USE'

32 PRINT: PRINT

33 END 


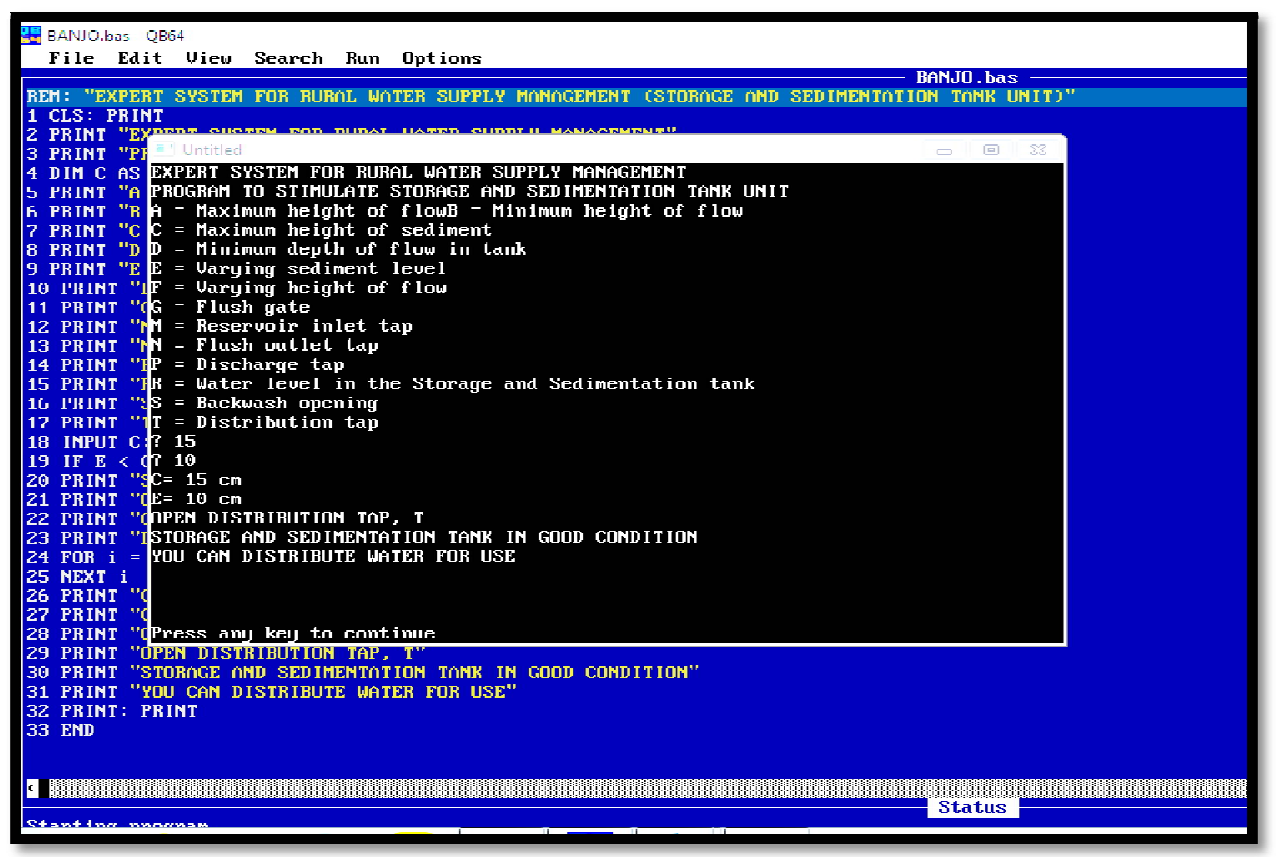

Untitled

$\square$

EXPERT SYSTEM FOR FURAL WATER SUPPLY MANAGEMENT

PROGRAM TO ST IMULATE STOFAGE AHD SEDIMENTAT IOH TANK UNIT

$\hat{A}=$ Maximum height of $f$ lowB $=$ Minimum height of $f$ low

C - Maximum lat ighl uf sed iment

D = Minimum depth of flow in tank

$\mathrm{E}=$ Uarying sediment leuel

$F=$ Uaruing lueight of $\mathrm{T}$ low

$\mathbf{G}=\mathbf{F l u s h}$ gate

$\mathbf{y}=$ Reseruair inlet tap

Y Flush outlet tap

$\mathbf{P}=$ Discharge tap

A = Water level in the Storage and Sedimentation tank

$\boldsymbol{S}$ = Backwash open int

$T=$ Distribution tap

? 15

720

$\mathrm{C}=15 \mathrm{~cm}$

$\mathbf{E}=20 \mathrm{~cm}$

Press any key to continue 1

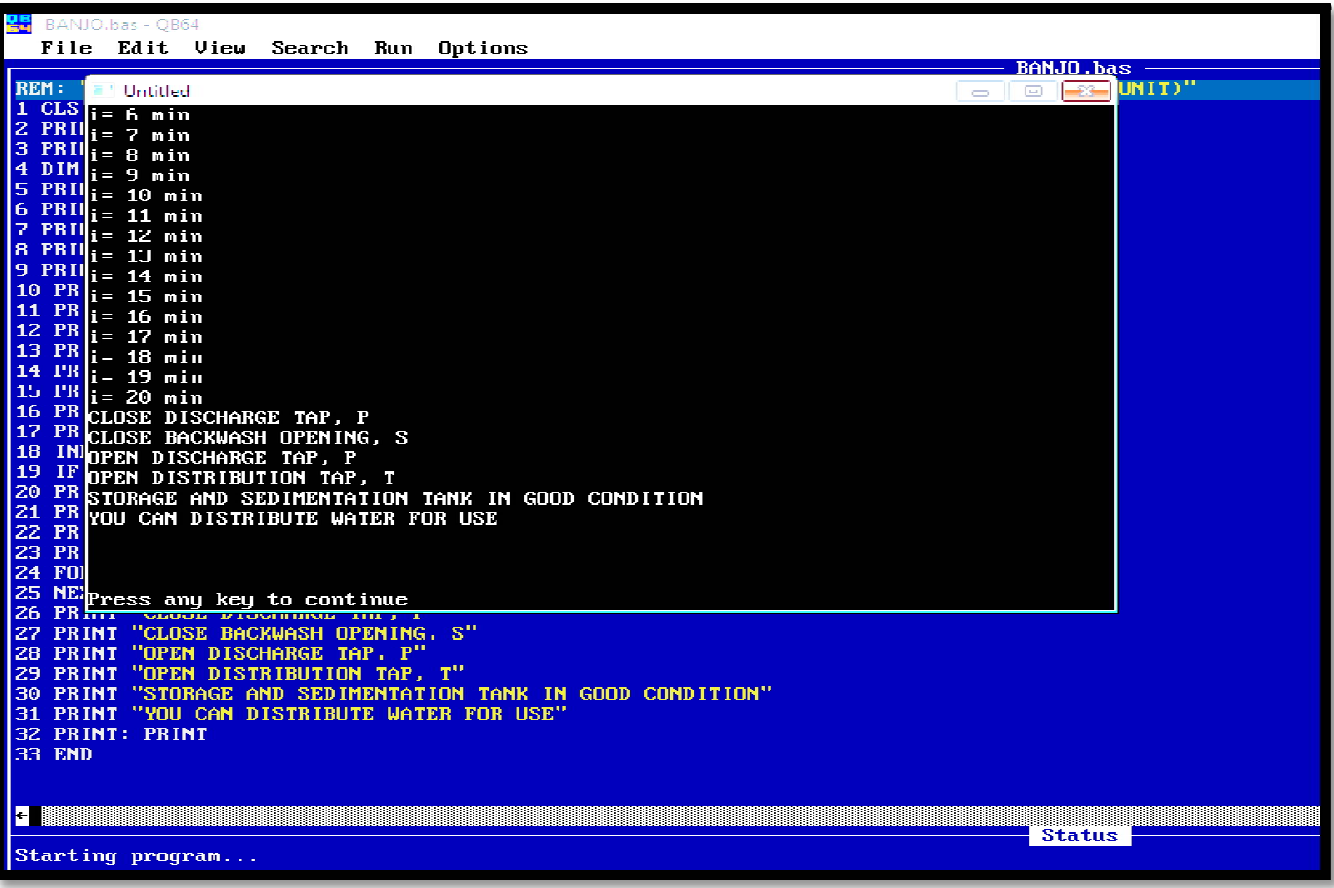

Figure 5: Output Interface 1: Storage and Sedimentation Tank Unit 


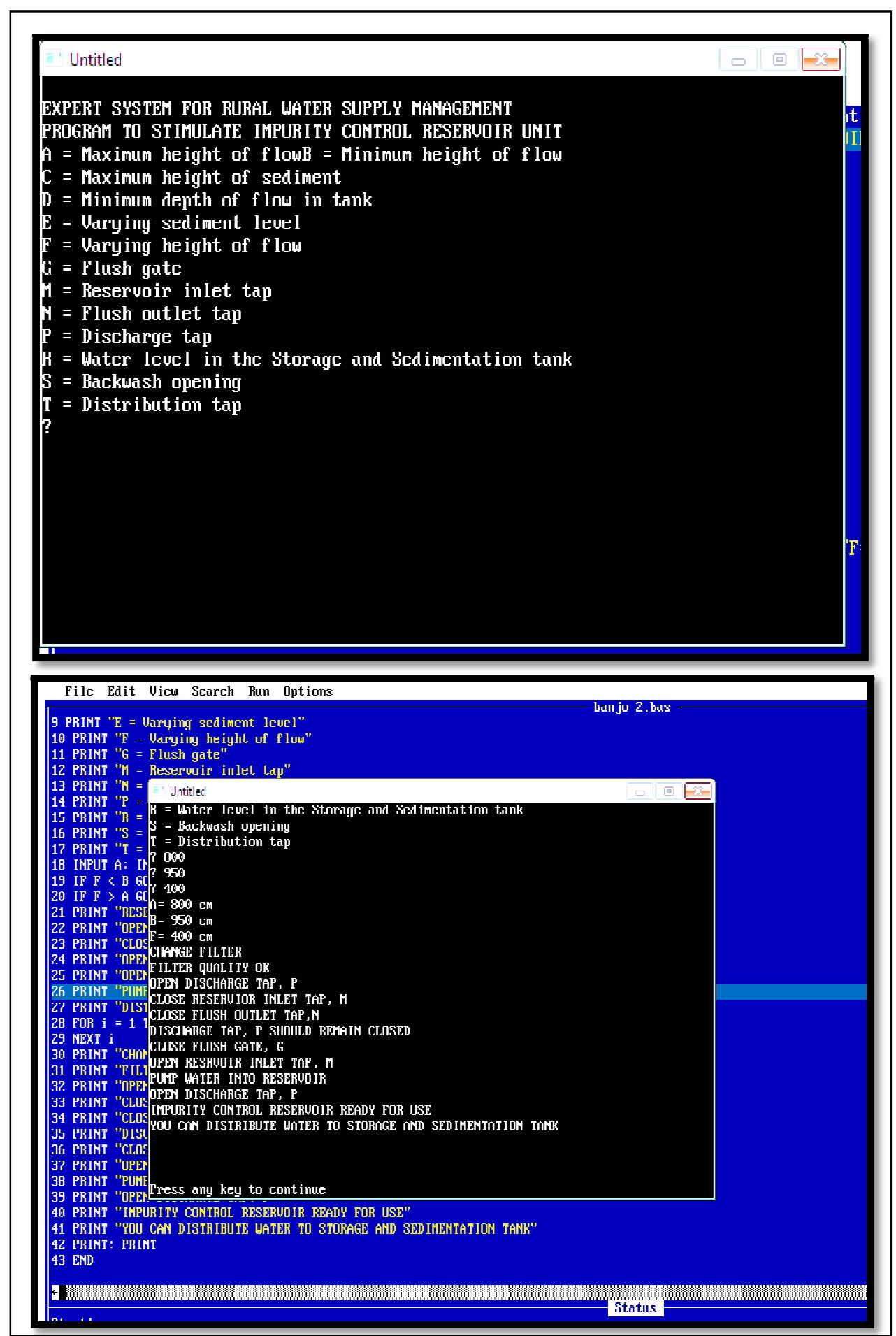

Figure 6: Output Interface 2: Impurity Control Reservoir

\section{Discussion}

\subsection{Operational Principles of the Expert System}

Starting with the impurity control reservoir; as the water is pumped from the mini dam into the reservoir, the discharge tap, ' $\mathrm{P}$ ', on the reservoir remains closed until the water reaches level ' $\mathrm{B}$ ' (the designed minimum height of flow) in the reservoir. At this water level, the lower sensor senses the signal and transmits it to the computer system unit that will notify the operator to open the discharge tap ' $\mathrm{P}$ ' and pump water into the storage and sedimentation tank. Meanwhile, the distribution tap on the storage tank remains closed until the water reaches level ' $D$ ' (the designed minimum flow depth). When water level gets to ' $D$ ', the minimum flow depth detector ' $K$ ' would signal to computer system unit while the computer system would alert the operator to open the distribution tap, ' $\mathrm{T}$ '.

A coagulant is added to the water contained in the storage and sedimentation tank. This would allow any remnant sediment being carried from the impurity control reservoir unit to settle at the bottom of the tank. The sediment level in the tank would continue to increase as the usage of the tank progresses. 
By the time sediment level reaches point ' $C$ ' (the designed maximum sediment level) in the tank, the sediment sensor would signal to the computer system while the computer alerts the operator to open the back-wash opening, 'S' and close the distribution tap ' $\mathrm{T}$ '. The remaining water in the tank together with the incoming water from the impurity control reservoir water would be used to wash the tank. The water used in washing the tank passes through a pipe connected to the backwash opening to the 'discharging pipe for irrigation activities'. The water could then be used for irrigation or other agricultural work. The washing process is allowed for about 20 minutes after which the backwash opening is closed and the cycle continues.

Back to the impurity control reservoir, as its usage continues, its filter begins to deteriorate. The deterioration progresses with time, the pores in the filter begin to block with the dirty particles, which the filter is removing from the water. This is indicated by the hydraulic head loss across the filter as a result of increasing frictional resistance which the filter presented to the passage of water; and deterioration in the quality of water filtered. When the filter deteriorates to certain point, the water would increase to certain level, 'A' (the designed maximum height of flow in impurity control reservoir) which would in turn sense the upper sensor. The signal from the upper sensor is passed to the computer system unit which would eventually alert the operator to close the discharge tap, ' $P$ ' and open the flush gate, ' $G$ '.

The flush gate is connected to the pipe leading to the 'discharge pipe for irrigation' hence, the water from the flush gate flows through. The sand is washed away and the gravels are thoroughly cleaned by the water being pumped from the dam. The process of washing is done for about 20 minutes after which the computer would inform the operator to close the reservoir inlet tap, ' $\mathrm{M}$ ', and replace the sand filter, while the discharge tap ' $\mathrm{P}$ ' remains closed and the cycle continues.

\section{Conclusion}

There is need for better management system that would bring about comfort to rural settlers (being the largest agricultural producers) in terms of water supply in order to boost agricultural production. The technique required for this better management might require combination of knowledge from different disciplines related to agricultural engineering. This expert system would bring about timeliness of water supply operations, less drudgery in the supply management, with minimal operational cost and provide for further researches and development in water conservation management.

Further research should be done on conceptualizing a design for modern water purification materials and its integration in an expert system, Optimization of hydraulic models in hydraulic structures for water use management and supply and Development of expert system for farm irrigation and water conservation.

\section{References}

i. Abdullah, W., Abdullah, N., Marion, J.-M., Quiedat, M., \& Chauvet, P. (2020). A Hybrid Methodology for Short Term Temperature Forecasting. International Journal of Intelligence Science (IJIS), V0l. 10 (3): pp 65-81.

ii. Akhund, M. A., AbdulRahman, I., \& Memon, I. (2014). A review on Expert System and its Applications in Civil Engineering. International Journal of Civil Engineering and Built-Environment (IJCEBE), Vol. 1: pp. 24-29.

iii. Centres for Diseases Control and Prevention (CDCP) (2014). 1600 Clifton Rd. Atlanta, GA 30329-4027, USA.

iv. Kuman, Y.,\& Jain, Y. (2012). Research Aspect of Expert System. International Journal of Computing \& Business Research. ISSN (online): 2229-6166.

v. McCorduck, P. (2004). Machine Who Think, 2nd edition. Natick, MA: A. K. Peters, Ltd. ISBN 1-56881-205-1.

vi. Morgan, P. (1990). Rural Water Supply and Sanitation. Macmillan Education Ltd., London.

vii. Nilsson, N. J. (2010). The Quest for Artificial Intelligence: A History of Ideas and Achievements; $1^{\text {st }}$ edition. Cambridge University Press, New York, NY 10013-2473, USA.

viii. Nwigbo, S. \& Agbo, O. C. (2011). Expert system: A Catalyst in Educational Development in Nigeria.

ix. Oluwande, P. A. (1983). Guide to Environment to Tropical Health Environmental Engineering. Nigerian Institute of Social and Economic Research, Ibadan, Nigeria.

x. Parkinson, S. \& Longstaff, A. P (2015). Multi-objective Optimisation of Machine Tool Error Mapping using Automated Planning. Journal of Expert Systems with Applications, 42 (2015), 3005-3015.

xi. Peter J. F. Lucas (2014). Principles of Expert Systems. Centre for Mathematics and Computer Science, Amsterdam.

xii. Ramesh, H., Santhosh, L.,\& Jagadeesh, C. J. (2012). Simulation of Hydraulic Parameters in Water Distribution Network Using EPANET and GIS. International Conference on Ecological, Environmental and Biological Sciences (ICEEBS'2012) Jan. 7-8, 2012 Dubai.

xiii. Wei, Y., Feng, Q.,\&Yuan, S. (2020). Differential Evolution Algorithim Based on Ensemble of Constraint Handling Techniques and Multi-Population Framework. International Journal of Intelligence Science (IJIS), V0l. 10 (2).

xiv. Yelapure, S. J.,\& Kulkarni, R. V., (2012). Literature Review on Expert System in Agriculture. International Journal of Computer Science and Information Technologies (IJCSIT), Vol. 3 (5), 5086-5089.

xv. Zhao, S., Mao, X., Lin, H., Yin, H.,\& Xu, P. (2020). Machine Learning Prediction for 50 Anti-Cancer Food Molecules from 968 Anti-Cancer Drugs. International Journal of Intelligence Science (IJIS), V0l. 10 (1). 